\title{
Analyzing and Applying the Technology of Online Instruction
}

\section{Based on an Introductive Nutrient Nutrition and Health Class}

\author{
Zhaoyi $\mathrm{He}^{1, *, \dagger}$, Yuhao Liang ${ }^{2, \dagger}$, Yang Zhou ${ }^{3, \dagger}$ \\ ${ }^{1}$ Department of Physics, University of California, Santa Barbara, California, 93107, U.S.A. \\ ${ }^{2}$ Guangzhou Foreign Language School, Guangzhou, Guangdong, 511455, P.R.C. \\ ${ }^{3}$ Oxbridge Academy, West Palm Beach, Florida, 33409, U.S.A.

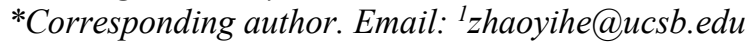 \\ These authors contributed equally.
}

\begin{abstract}
This paper designed an introductive Nutrition and Health Class for grade 11 with the technology provided by the online instruction platform Nearpod, based on pedagogical research and theory. We further analyze the effectiveness and benefits of the technology we applied technically and pedagogically. The paper consists of four sections: In the Introduction, we introduce the background and the reasons for combining liberal education of Nutrition with online education basing on the studies of teenager dietary patterns from the USA and Hong Kong over a decade. In Analysis, we further discuss the advantage of online education and its technology compared with traditional education in four aspects: facility, discussion, group dynamic, and feedback. In Pedagogy and Technology, we discuss the strategies for improving online education based on pedagogical research and theory. In Course Content, we design an online course about liberal education of nutrition and health for Grade 11, taking advantage of the online course platform Nearpod. We introduce the basic construction and the purpose of the course. The purpose of the course is to raise students' interest in nutrients and health and apply the knowledge to improve their eating patterns by introducing them to the basic knowledge of Carbohydrates and health. In Conclusion, we summarize the previous discussion and further examine the pedagogical potency of the technology.
\end{abstract}

Keywords: Traditional Class, Online Class, Liberal Education, Course Design, Nearpod, Technology, Pedagogy, Nutrition and Health

\section{INTRODUCTION}

The relationship between food and health is complex and continuously evolving with recent increased awareness of nutrients. Especially, Teenagers are in a crucial stage of growth and development considerably relies on a well-balanced diet. With the growing unhealthiness of teenagers' eating patterns [1-3], promoting healthier dietary patterns among teenagers has been a worldwide topic. Based on a study of 203 adolescent high school students in Hong Kong, liberal education of nutrition and health is shown helpful in helping students adopt healthier eating patterns and lifestyles [4]. Meanwhile, with the development of communication tools, the internet, and globalization, online education has become an important element in education [5]. It gives instructors and students more flexibility of time and space, class choices, reduces costs, and improves efficiency in communication [6]. In our paper, we will review the papers and research related to online education, liberal education, and nutrient and health education to explore the advantages of online education and take the advantages to design an online introductive course on nutrition and health.

\section{ANALYSIS}

\subsection{Importance of Liberal Education of Nutrition and Health Among Teenagers}

Comparing the studies of USA and Hong Kong teenagers' eating patterns in 1996, 1997 and that in 2006, the data of dietary patterns show a growing rate of inadequateness to the standards of good health. Their 
patterns usually include growing intake of high sugar (carbohydrates) or fat [1-3]. The intake of carbohydrates and fat is growing at a notable rate mainly because of the preference of snack food products over diseasepreventing foods, including vegetables and fruits. Moreover, the physical activity of both the USA and Hong Kong population is found to be inactive, which makes the matter worse. People's life-long eating patterns are usually based on dietary performance at a young age. Therefore, it is of great significance to help teenagers build up healthier eating patterns and lifestyles to address this issue. Liberal education of nutrition and health has shown to led positive effects on teenagers' diet hobby. Diet is vital in preventing certain cancer and diseases such as diabetes [7].

A study of 203 adolescents high school students in Hong Kong shows that nutrition education programs in introductive classes can play an important role in improving students' basic knowledge, dietary habits, and physical activities. A liberal education of nutrition and health is shown helpful in helping students to adopt healthier lifestyles [4]. The researchers recorded and examined the teenage experimenters' Body Mass Index, exercising patterns, and dietary patterns before the liberal nutrition and health education. Three months later, the researchers conducted a follow-up action. The teenagers were more awarded and took more control over their eating patterns and physical activity, revealing a positive relation between liberal education and physical activity and diet management.

\subsection{Comparing Online Education with Traditional Education}

With the developing technique of teaching and online education, to construct a class with greater flexibility and efficiency, we will build an online introductive course for nutrient and health liberal education. Traditional education refers to offline faceto-face education, requiring students to locate in the classroom or campus in person rather than attend online lectures. Traditional education sometimes requires hands-on experiences that can only be accomplished in the laboratory on campus, which is hard to achieve effectively through online education [8]. Online education, also known as e-learning or distance education, is a fully-online course that uses technology to deliver independent of time and space, and it also uses multimedia technologies and the Internet, which access to facilities and services; information and communication are combined to enable the access to various resources [8].

However, unlike advanced classes that need students to develop practical skills, the online course topic is about introductive nutrients, which rarely requires students' experimental practice. Therefore, online classes can be optimal for instruction.
The comparison of traditional teaching and online teaching can be discussed in four aspects: facility, discussion, group dynamic, and feedback. The ability of contact continues in online teaching with various sorts of online meeting software. The techniques make it even more convenient by breaking the time zone and space barriers, while traditional teaching has only face-to-face interaction within one set of time frames and places. On the other hand, the immediate interaction of traditional classes is less infected by a technical issue, and the feedback is timelier. However, a more stable network and higher requirements of multiple functions software and tools can make up this issue. Moreover, when it comes to group dynamics, online classes give less sense of anxiety and more equal, traceable participation [8]. In traditional classes, one of the most irreplaceable advantages of online classes is that they are recordable. Therefore, students can have permanent access and can be active listening even without participation [8].

Comparing with the traditional teaching mode, online education has greater flexibility, providing more programs and schedules for students to choose from; it also helps save time and money since students can study at home without worrying about traveling. Online education also breaks the boundaries of space, for an unlimited number of students can attend the class, even if they are on the other side of the globe. Sometimes the traditional education would be costly to maintain because the corresponding institutions need to spend a considerable amount of time, money, and effort on school facilities. But when it comes to online education, it is relatively less expensive, for the Internet connection, software, and the corresponding facilities need fewer resources to sustain [6].

For students, online education provides more opportunities for discussion; they will be more motivated to interact with each other, like asking questions or exchanging different perspectives [9]. Moreover, online education allows the use of the Internet, which gives students access to a large amount of information, including literature reviews, videos, charts, thus enhance students' understanding of those complicated theories and their learning efficacy. In addition, online learning gives students chances to adjust their study modes, since, in traditional education, some of the students cannot catch up the curriculum progress, but they can follow their own pace in online education, such as reviewing the lecture recording videos; therefore, it can increase students' satisfaction and reduce their stress [9]. Indeed, it is admittedly that online learning requires self-discipline [10], and professors may not know what students are actually doing. To solve this problem, we meticulously design an online course that includes various activities that require students' full attention and participation. 
Online learning often uses discussion boards, synchronous chat, e-mails, and other tools. There's less pressure and tension for students of online learning than those of face-to-face learning, especially for those hesitant students [6]. While students choose online classes, their overall anxiety is likely to decrease, which will give students advantages in the following aspects: 1) They would ignore the instructor and thus participate in the discussion more easily; 2) The depth of analysis often increased; 3) Each student can get better-detailed feedback; 4) Loose -bound nature will promote students to conduct adventitious learning [8]. These effects are harder to achieve in face-to-face learning mode because students are more likely to have certain degrees of anxiety. Even though online learning may not guarantee grades as good as that of traditional education, online learning will be ahead of in-person learning in a comprehensive way in the discussion.

When designing online lectures, teachers can offer students online technologies and information access that simulate the environment and condition of the school laboratory and library. And these are already enough for all of them to go through the whole online lecture. Traditional education can offer students a mass amount of study materials, including all the books and papers; professors can provide students with these materials, and students themselves can also go to the library to look for the resources they need. However, the online classes have all the learning materials in electronic form or editions to send to students. Moreover, since we can simply send students URL links or online documents, it is much more convenient, and students don't have to waste time in the library to pinpoint the materials they need. The effectiveness of the online resources is the same as the paper teaching materials.

Online courses enable teachers to provide each student with more detailed feedback because there are techniques to record each students' performance. For example, teachers can know which kinds of questions students usually make and their frequent mistakes. Therefore, based on these data, teachers can give each student more detailed feedbacks, and teachers can also determine the focus of the class. However, in traditional courses, teachers may not have enough time to analyze each student's performance, which means they can only give rough feedback and decide the focus of the class from the general impression of students' performance. In online classes, more students can give others feedbacks because students cannot "hide" in class. For example, teachers can mark the participation of students according to the recording of the online courses so that students cannot muddle through. On the contrary, in traditional classes, some students choose not to give feedback to others due to the lack of recording function. In this way, a considerable number of students cannot obtain feedback from others and thus cannot further improve themselves.

\section{PEDAGOGY AND TECHNOLOGY}

A variety of technologies is put into the instruction. The lecture was set on an online teaching platform Nearpod, which allows teachers to establish classes and allows students to participate collaboratively, enhancing the connections and interactions of both students and teachers; students can express their opinion on the platform, and teachers can obtain immediate feedbacks; multiple media can be applied for a better demonstration. With Nearpod, students can join multiple activities we designed, including Open-ended questions, Video, Slideshow, Quiz, Collaborative board, Nearpod 3D, Web content, Draw it and Matching pair to enhance students' understandings of the content, and teachers can regulate the class basing on the timely feedback [11].

Group discussion and the Nearpod 3D effectively illustrate the digestive progress of carbohydrates. The media technology makes the demonstrations more understandable. It leaves a more profound impression of the $3 \mathrm{D}$ model. one disadvantage of online instruction might be that students are less engaged in the class. However, using a discussion board, Web content, and poll can help increase communication and engagement [9]. The usage of slideshows will give students a visual image of the content.

Matching pairs and quizzes are opportunities for students to test what they've mastered and provide remediation for them. These test activities link up the significant sections of our lecture. Plus, those activities also enable teachers to gain feedback and regulate the class; after obtaining students' paces, teachers can know whether the lecture is suitable for students or not.

The usage of the concept map, a formal and structured mapping tool, allows students to clearly learn carbohydrates' classification [12]. Possessing hieratical and chronical structures, the concept map offers an excellent opportunity for students to find the interrelation of carbohydrates. While drawing the concept map, students can know specifically which parts of carbs they do not understand.

\section{COURSE CONTENT}

The focus of this introductive course on nutrients and health is Carbohydrates. Various pedagogical strategies can be applied in this online class. There are group activities to improve students' participation and confidence visualized technologies serving as cognitive tools including slideshows, videos, Nearpod 3D, and concept maps for more concrete understanding. Other activities like web tools and quizzes are also utilized to enable students to take what they learn into practice. Besides, poll, open-ended questions, and collaborative board in the lecture provides chances for higher-level thinking and share perspectives with others, acquiring 
new understandings, and collecting effective feedback to both students and teachers.

The slideshows containing knowledge cards summarize the classification and the structure of carbohydrates to stimulate students' critical thinking, encouraging them to connect the contents and images [13]. The literal part might be abstract; this visually appealing slideshow can help them connect different complex definitions together. Therefore, Slides show's utilization can help students summarize information, separate each part, and differentiate the subject when searching and refining information during the review.

To promote students' interests, we also offer "openended questions" to recall their own experiences. Plus, teachers also help students to complete higher-level thinking. Besides, teachers would have a chance to adjust the path of the class since it shows their previous knowledge, achieving more creativeness and feedbacks. Moreover, open-ended questions sum up and test students' ability to integrate the entire class at the end of the lecture. Both students and teachers can gain valuable feedback [11].

We also apply the concept map to this course, which raises the level of the task. After studying simple carbs and complex carbs, students will be assigned to draw an appropriate concept map. We will also provide an example of a concept map to make sure they understand the basic structure of the concept map. Rather than the low cognitive task of simply memorizing, the mapping task allows students to correlate the knowledge they have learned [12]. Thus, the concept map gives students a concise overview of the topic and to visualize cognitive structures.

Nearpod 3D serves as a cognitive tool to reduce confusion by visualizing the digestive process. According to the research from Mahatma Gandhi Memorial Medical College, in the subject of anatomy, the group discussion can help improve the performance and skills in both spoken and activity in a significant level by improving students' engagement and the climate of the classroom, reducing fear and uncertainty of the digestive progress by talking and sharing peerknowledge with classmates, especially for poor performers [14]. It can increase students' ability to communication and problem-solving.

We use video as supplementary learning. Selflearning with video can empower them to learn flexibly and independently. Moreover, it plays a role in the development of critical thinking. The stimulation from the design, graphic and content types of multimedia can raise more emotional engagement and therefore leave more impressions about the knowledge [15]. Finally, we examine students' learning outcomes with a matching pairs challenge. It serves as a review, self-check, and feedback for teachers, and it also forecast that the subject is changing and allow students to pace and wrap up themselves.

The web tool gives students a chance to put the knowledge into practice. Calculating the carbohydrate intake based on their body index can verify whether they fully understand the content. The collective poll activity requires students to combine the definitions with their status to leave a deeper impression by calculation. It also enables students to have high-level thinking, enhancing their problem-solving capacities and understanding complexity and ambiguity [16]. It adds engagement to the class and enables students sharing gain peer information as well.

At the end of the lecture, we will provide a collaborative board activity asking what students have learned from this class and the trouble they face or some extended topic they want to share. This brainstorming activity enhances students' critical thinking and provides effective feedback for teachers [11]. Students can also see what other students post on the board, providing a chance and time for new understanding.

\section{CONCLUSION}

Liberal education of nutrition and health among teenagers helps improve students' basic knowledge, dietary habits, and physical activities and further adopting a healthier lifestyle. Comparing with traditional classes, online teaching generally differs in the facility, group dynamic, and feedback. Online classes have irreplaceable advantages, including more time and space availability, permanent access, and active listening even without participation. However, online classes are more dependent on media and devices and more likely to be affected by technical issues, which more powerful devices can solve and software can be an effective solution. Online education is therefore effective and full of potentials in liberal education. The technology combining with pedagogy has more potentials to achieve more than traditional education.

Showing the importance and potential of online education and the necessity of liberal education of Nutrition and health, the Nearpod class we designed is a typical example to explore the online teaching technology for liberal education. The development of online liberal classes is possible and promising since it contains all the significant content that students need to master, and it could achieve our teaching objectives. The technology we used in this class can promote students' learning process and provide some function that is impossible or impractical in traditional education. The technology-based teaching strategy makes the class process much more effective for both teachers and students. In the future, more types of liberal education with online teaching technology will be discussed and explored. 


\section{REFERENCES}

[1] Krebs-Smith, S. M., Cook, D. A., Subar, A. F., Cleveland, L., Friday, J., \& Kahle, L. L. (1996). Fruit and vegetable intakes of children and adolescents in the United States. Archives of pediatrics \& adolescent medicine, 150(1), 81-86.

[2] Peterson S., Sigman-Grant M. (1997). Impact of adopting lower-fat food choices on nutrient intake of American children. Pediatrics; 100: E4.

[3] Tse MYM, Benzie IFF. (2006). Personal perspective of a group of nursing students in Hong Kong on diet and health; implication for nurse education. Asian J. Nurs.; 9: 74-77.

[4] Tse, M. M. Y., \& Yuen, D. T. W. (2009). Effects of providing a nutrition education program for teenagers: Dietary and physical activity patterns. Nursing \& Health Sciences, 11(2), 160-165. https://doi.org/10.1111/j.1442-2018.2009.00443.x

[5] Mayadas, A., Bourne, J., \& Bacsich, P. (2009). Online Education Today. Science,323(5910), new series, 85-89. Retrieved September 8, 2021, http://www.jstor.org/stable/20177127

[6] Ni, A. (2013). Comparing the Effectiveness of Classroom and Online Learning: Teaching Research Methods. Journal of Public Affairs Education, 19 (2), 199-215. Retrieved August 26, 2021, http://www.jstor.org/stable/23608947

[7] World Health Organization. (2003). Diet, nutrition, and the prevention of chronic diseases: report of $a$ joint WHO/FAO expert consultation (Vol. 916). World Health Organization.

[8] McConnell, D. (2000). Implementing computer supported cooperative learning. London: Kogan Page Li.

[9] Arkorful, V., \& Abaidoo, N. (2015). The role of elearning, advantages and disadvantages of its adoption in higher education. International Journal of Instructional Technology and Distance Learning, 12(1), $29-42$. https://www.itdl.org/Journal/Jan_15/Jan15.pdf\#pag $\mathrm{e}=33$

[10] Behzadi, Z., \& Ghaffari, A. (2011). Characteristics of online education and traditional education. Life Science Journal, 8(3), 54-58. http://www.lifesciencesite.com/lsj/life0803/011_57 19life0803_54_58.pdf

[11] Hattie, J., \& Timperley, H. (2007). The power of feedback. Review of Educational Research, 77(1), 81-112.
[12] Davies, M. (2011). Concept mapping, mind mapping and argument mapping: What are the differences and do they matter? Higher Education, 62(3), 279-301.

[13] Harris, B. R. (2005). Big Picture' Pedagogy: The Convergence of Word and Image in Information Literacy Instruction. ACRL Twelfth National Conference.

https://www.ala.org/acrl/sites/ala.org.acrl/files/cont ent/conferences/pdf/harris05.pdf.

[14] Bose, A. \& Jehan, M. (2018). Impact OF “Group Discussion" As A Teaching-Learning Method On Performance of Poor Performers in The Subject of Anatomy.

[15] De Gagne, J. C., Kim, S. S., Schoen, E. R., \& Park, H. K. (2018). Assessing the Impact of Video-Based Assignments on Health Professions Students' Social Presence on Web: Case Study. JMIR Medical Education, 4(2), e11390-e11390. https://doi.org/10.2196/11390

[16] Pich, M. T.; Loch, C.H.; and De Meyer, A. On Uncertainty, Ambiguity, and Complexity in Project Management. (2002). Management Science. 48, (8), 1008-1023. Research Collection Lee Kong Chian School of Business. 